\title{
SUBJECTIVE PERCEPTIONS OF SUCCESS IN TOP-CLASS TENNIS PLAYERS
}

\author{
Michelle L. JACKSON \& Helgo H. SCHOMER \\ Department of Psychology, University of Cape Town, Cape Town, Republic of South Africa
}

\begin{abstract}
This paper explores the subjectively perceived performance success of top-class tennis players, largely in an effort to supplement the massive body of purely cognitive, psychophysiological sport psychology literature that already exists. Indepth, semi-structured interviews were conducted individually with nine players at three levels of expertise: provincial, national, and international. The players also completed the Telic Dominance and Negativism Dominance Metamotivational Scales, in line with the Reversal Theory of emotion and motivation. Cyclical thematic analysis of the interview texts and descriptive statistical analysis of the scale items were carried out. Ten integrative theme clusters emerged exploring what it means to be successful in tennis, including nine themes illuminating the elements subjectively perceived as necessary to achieve success. Some significant differences were found in certain theme categories for provincial, national and international players. The scale scores supported and questioned previous research that success in sport is related to paratelic and negativistic metamotivational dominance.
\end{abstract}

Key Words: Reversal theory; Metamotivational dominance; Subjective perceptions of success; Self-belief; The "edge"; Individual strengths;

Emotional reactivity.

\section{INTRODUCTION}

Tennis is an available study in the psychology of personality. Through observing the characteristics of players who reach the top, it is possible to speculate on what elements ensure success in professional tennis. Apart from this intuitive approach to understanding how tennis players (and athletes in general) perform and behave, empirical studies have investigated what drives sports professionals and which factors ultimately determine their success.

Sport psychology has largely been dominated by a cognitive or information processing approach to the behaviours and motivations of athletes. Much research has focused on mental practice, specifically the mental practice needed for sequences of movement during athletic performances (Kremer \& Scully, 1994: 100). In addition, the concepts of retention and forgetting are now well established in the sport science literature. Other research has examined the effect on sport performance of massed and distributed practice, whole and part methods, blocked and random practice and the transfer of learning. While valuable, this research concentrates mainly on motor skills as factors impacting on performance success (Kremer \& Scully, 1994). Furthermore, the narrow focus on this area of research, as comprising the heart of sport psychology, is problematic. 
Kerr (1997) suggests that what is missing within the sport psychology literature is a lack of theory and, furthermore, that there is an "excessive adherence to traditional methodologies" (Schutz, 1994 cited in Kerr, 1997: 189). While the reliance on empirical methods is an accepted practice of psychophysiological research, this study suggests that this focus needs to be challenged. Empirical research routinely ignores the relationship between subjective feelings (e.g., motivation, personality and affective factors) and athletes' performance (Kerr, 1997). The present study argues that the brilliance of athletes needs to be assessed from their own subjective standpoints. A focus on the subjective perceptions of athletes may help coaches and players to discover something more about what differentiates the champions from those who never quite make it to the top. Since equality of physical performance in the sport is becoming more and more apparent, it seems likely that this crucial distinction is a result of mental performance and talent.

\begin{abstract}
AIM
This study investigates how top-class tennis players subjectively perceive success in their game. The aim is to gain an overall understanding of the personal experience of tennis players at three varying levels: provincial, national, and international elite; in order to identify what they regard as the basis of a satisfying performance or career, and to outline the characteristics that lead to success in professional tennis. A further aim of this study is to identify salient differences among the aforementioned groups, and to explore the possible reasons for these discrepancies.
\end{abstract}

\title{
LITERATURE REVIEW
}

Reversal theory provides an appropriate theoretical framework for the study. It proposes that people alternate between four pairs of metamotivational states that they possess, allowing for 16 different state combinations. The pairs of states are Telic-Paratelic (arousal-avoiding and goal-directed versus arousal seeking, spontaneous and sensation-oriented), ConformistNegativistic (compliant and cooperative versus rebellious and stubborn), Mastery-Sympathy (desire to compete versus desire for harmony) and Autic-Alloic (concern with self versus concern with others) (Kerr, 1997). A tennis player about to serve for the championship title at Wimbledon is most likely in the telic-conformist-mastery-autic state.

Reversals between states are mediated by metamotivational dominance (which state of each pair one most often tends towards); protective frames (how arousing the individual subjectively perceives a situation to be); and reversal inducing agents (e.g., frustration, satiation and contingent events) (Kerr, 1997). Acts are classified according to the actor's subjective interpretation thereof (e.g., conformist as opposed to negativistic) (Kerr, 1997). Furthermore, the theory accounts for human inconsistency (Apter, 2004) by introducing the concept of multistability: personality is explicable in terms of "patterns of change"; "we not only differ from each other, but also, over time from ourselves" (p. 2).

Tennis requires impulsive actions (new movement and skill combinations are constantly needed during play) and is thus classified as an explosive sport (similar to surfing, baseball, cricket, basketball, touch football, windsurfing and soccer) (Kerr, 1997; Diehm \& Armatas, 2003). As such, it is a predominantly paratelic sport. Contrastingly, a preference for endurance sports, which are characteristically repetitive and monotonous (e.g., long-distance 
running, cycling and rowing), usually indicates the planned lifestyle orientation of telic metamotivationally dominant people (Kerr, 1997). The association between lifestyle and sport preference, as well as between particular states and success in sports, has been investigated by a number of researchers. For example, Apter (1982 cited in Kerr, 1997) found the negativistic state to be associated with creativity in sport. Additionally, Braathen and Svebak (1992 cited in Kerr, 1997) found that sport professionals with a high score on the proactive Negativism Dominance Scale (NDS) had reached a higher level of excellence in their sport.

A useful model for the present study is The Inner Game of Tennis, conceptualised by Gallwey (1975), who believes that the relationship between the two selves in a tennis player determines a player's "ability to translate his knowledge of technique into effective action" (p. 25). The conscious, instructing Self 1's mistrust of the unconscious, automatic, but fully competent "doer", Self 2, is the source of faulty performance in a player's tennis game (pp. 25-26). Concentration and "quieting the mind" (p. 33) are the solutions. Cognitive research parallels the Inner Game, suggesting a corroboration of quantitative and qualitative approaches. Concentration in sport is seen as identical to normal attention in everyday cognitive perceptual experience. Athletes identify "'advance cues' that are relevant to the task at hand while 'screening out' distractions" (Abernethy, 1987 cited in Moran, 1996: 77). Most studies are psychophysiological in nature and focus on how physiological arousal involuntarily narrows an athlete's attentional focus, leading to a decrease in quality of performance (Moran, 1996).

Furthermore, Syer and Connolly (1984) propose that sport performers may be either neurotic or creative competitors. The former are seen to be motivated by extrinsic circumstances, desiring the win to boost their deficient self-esteem, or to "measure up to some external standard" (p.148); while the latter are seen as self-assured, confident and purposeful, engaging in sport to express and exercise their inner resources (p. 148). These descriptions of the creative competitor are reminiscent of paratelic dominance. The connection between subjective perceptions of success and the labels above is of interest in the present study.

\section{METHOD}

\section{Sample}

Case selection was purposive since the desired population is naturally small, and individuals therein have specific characteristics, on which the study focuses. Three international, two national and four provincial players were recruited. All the players except one of the international participants (a British player) were South Africans. While it would have been desirable to have a larger sample, the small sample was felt to be sufficient for the present study, as it is exploratory and qualitative in nature thus focusing on obtaining in-depth accounts rather than large quantities of data. Furthermore, owing to the high profile of professional tennis players, access was a constraint. Fortunately, however, the following helpful contacts assisted as gatekeepers in this regard: a member of the Lawn Tennis Association (LTA) who formerly personally looked after players during the major tournaments, and a South African tennis player, who was ranked in the top ten for doubles and serves as a Players' Representative for the Tennis Players' Union. 


\section{Instruments}

Semi-structured interviews were conducted with players to discover their subjective perceptions of success. The interviews comprised different areas of enquiry intended to generate conversation about the inner world of top-class tennis players such as: background information to contextualise the interviewees in the tennis world; what they understood to qualify as success in tennis; their opinions on the "mental side" of tennis; and a comparison between the empirical research and their personal experiences. Since all but one of the players are South Africans, perspectives unique to this country were explored. Interviews were flexible, allowing for the emergence of unexpected, useful information. While it may be argued that this technique lacks reliability and validity, it was felt that a more flexible approach would allow for a more in-depth and personal exploration of the experience, motivation and behaviours of professional tennis players. Sacks (1984 cited in Miller \& Glassner, 1997) points out the potential reliability of such transcripts. Revisions were made on the basis of the pilot study and based on commentary made at the French Open and Wimbledon tennis grand slams.

Furthermore, the following two psychometric reversal theory scales were administered to each player, as it was felt that the data obtained from these would compliment the qualitative material: The Telic Dominance Scale (TDS) (Murgatroyd, Rushton, Apter \& Ray, 1978 cited in Kerr, 1997) and the Negativism Dominance Scale (NDS) (McDermott \& Apter, 1988 cited in Kerr, 1997). Since the TDS was developed for adults, only the two younger provincial players did not complete this scale. The TDS is scored on the following three subscales Seriousmindedness (SM), Planning orientation (PA), and Arousal avoidance (AA). The first aspect, however, is the defining scale of telic dominance (Kerr, 1997). Regarding the test's reliability, the Cronbach's alpha coefficients for the subscales are $\mathrm{SM}=.691, \mathrm{PO}=.655$, $\mathrm{AA}=.734$, Total $=.837$; test-retest reliability was evaluated over various time periods and was significant each time at the $\mathrm{p}<.01$ level (Murgatroyd, Rushton, Apter \& Ray, 1978 cited in Kerr, 1997). The NDS consists of 18 items, which were extracted by factor analysis of 137 items (McDermott, 1988a cited in Kerr, 1997). Further studies confirm its usefulness and meaningfulness by showing that a two-factor solution results from large item pools very similar to the original one used. Seven items load heavily onto each of the two factors, and these were interpreted as proactive and reactive negativism. Four filler items were included to disguise the purpose of the scale (Kerr, 1997: 208).

\section{Method of analysis}

Thematic analysis was used to analyse the interview material. This is a qualitative approach in which data collection, analysis and theory are highly interrelated (Babbie, 2001). Rubin and Rubin (1995 cited in Mouton, 2001: 198), describe how the analysis "begins while the interview is still underway...[and] tells you how to redesign your questions to focus it on central themes as you continue interviewing". Further themes and concepts emerge thereafter and the final analysis involves organizing, contrasting and integrating such themes into an "accurate, detailed, yet subtle interpretation" (p. 198) of the research. Qualitative methods of analysis are gaining respect as independent, largely intuitive and creative endeavours (e.g., Babbie, 2001; Janesick, 2004). Although language, the dominant tool of this type of research, inevitably "fractures" reality and experience (Miller \& Glassner, 1997: 127), it may be argued that quantitative, numerical-rendering statistical processes do the same. 
Themes were primarily drawn out and coded and subsequently integrated into broader emergent themes, which provided a basis for discussion in the absence of any comparable sport psychology literature (Squibb \& Schomer, 2004).

\section{Procedure}

Interviews were tape recorded with a small, unobtrusive Dictaphone. It was decided that written notes would not capture the complexity of interview information (such as the participant's tone, emotional undercurrents, emphases, and detail of contextual information). Tape recording allowed for the interviewer to concentrate on participants and on the content and atmosphere of the interview.

The psychometric scales were analysed with descriptive statistics. The metamotivational scales were scored as follows: for the TDS, one point was given when the telic alternative was chosen (these are specified in Kerr, 1997), and half a point was given for the "Not sure" item. Three subscale scores resulted, with a maximum of 14 points for each. The overall score of telic dominance could therefore yield a maximum of 42. Similarly, for the NDS, the negativistic alternative yielded 2 and the "not sure" item, 1. The maximum for each subscale score was 14 and the overall negativism dominance score was therefore a maximum of 28 (Kerr, 1997).

\section{RESULTS AND DISCUSSION}

\section{Qualitative}

\section{Coding}

Coding resulted in primary thematic concepts, which, through cyclical analysis, memomaking and integrative recoding, were related to form various larger theme categories. Ten integrative theme clusters emerged outlining what it means to be successful in tennis, which included nine themes illuminating the elements subjectively perceived as necessary to achieve success in the game. The lack of literature surrounding South African sport proved problematic in terms of basing the analysis on established techniques. For this reason interviewees' responses were accorded great significance (Squibb \& Schomer, 2004). For confidentiality, the players' names were replaced with selected letters.

\section{Analysis}

\section{What comprises success?}

Each player was adamant about which factors determine success and what constitutes success in tennis. Through exploring which top players the interviewees deemed the most successful of all time, and why, it emerged that their primary measure of success was winning. Every player mentioned Wimbledon as the most desirable title to win - a title that bestows status and an aura of success.

International players took it for granted that winning (in the form of grand slams, other titles and rankings) is the essence of success in tennis. They glossed over questions relating to what success exactly is and concentrated more on how it is achieved. Contrastingly, A (national 
player) insisted that his personal success in tennis related to having reached a state of harmony and fulfilment, in which he enjoyed his life, owning a tennis club and imparting skills and wisdom to players. D (national player) confirmed this philosophy, emphasizing the original enjoyment that drew him to tennis, which he feels he loses with the pressure of competition. I (international player), however, related that winning in tennis has an addictive power that makes it enjoyable. The provincial players all regard making it professionally and winning titles as the core of a successful career. Only $\mathbf{H}$ (under 18 number one) added another proviso: enjoying the game. He did not, however, perceive such enjoyment as independent from winning, making the telling statement that, "the more you enjoy it, the better you'll play." These differences amongst the three levels of tennis players suggests that the level of success a player actually achieves (or expects to achieve, in the case of provincial players), possibly influences what they will admit as entailing true success.

\section{The dream begins it: Desire, commitment and determination}

The international players all committed seriously and without uncertainty to tennis at a young age. They termed it an emotional - not a logical - decision. B explained, "I mean, if you told me there was something I had to do to play tennis, to be a better tennis player, I would do it. I think that that's a huge part of things." I decided to go to Australia to train with a top coach, instead of going to university. The risk paid off: he qualified for the Australian Open that year, and then Wimbledon. The public often sees excluding other facets of life as sacrifice, but players perceive things differently. The love of the game and the desire to master it negates any perception of sacrifice. B stated, "to me it was just the way things were; it was the way it was meant to be done". The national players advocated a more balanced approach in terms of their commitment to playing tennis, while the provincial players discussed being reticent to commit to the game because of the low standard of tennis in South Africa.

\section{South African tennis}

All the players were adamant that substandard levels of South African tennis had a negative effect on their careers. The national and two South African international players felt that they would have been more successful had tennis in their country matched tennis overseas; and the provincial players were uncertain about how wholeheartedly they should commit themselves to the game, because of its questionable professional future in South Africa. This is highly problematic, as the data show a strong connection between desire/commitment and success in the game.

The chief problem the players cited was the lack of a professional attitude towards tennis in this country. B, the most successful player in the present study in terms of world rankings and titles argued that "our system is very far behind". He suggested that South African players lack competition exposure (there are too few people competing at top levels here, and no funding for them to travel frequently), and receive a standard of coaching that is "very low". Top South African players are defeated and discouraged by the intensity and dedication of overseas players. B insists that what South Africa's top upcoming players need is "somebody with the presence of mind to say, you're the number one or number two in South Africa, but you're still the number 50 in America. And only two of those 50 are ever going to make it. So if you want to be a professional tennis player, you're behind". 
The provincial players were well aware of the superiority of tennis overseas, with regard to professionalism; funding and scholarships; depth (a broad range of competition); status and monetary rewards. $\mathbf{H}$ has been offered a tennis scholarship to an American university and $\mathbf{G}$ (under 16 number one) aspires towards the same. E (under 14 number one) has a British passport and is investigating playing for Britain, as did his coach. South Africa's top young players are leaving, to grasp what they see as their only chance of "making it" in tennis. A, a former national player and current coach, says that he and many others in his position never said, "that's what I'm going to go and do, because there's nothing to do in this country". The sport is a focused business overseas, insists $\mathbf{A}$, and South Africa is far behind in its transition of tennis from an amateur to a professional sport. The recent scandalous disappearance of MTN funds for South African tennis and the organizations' refusal of Cell C's subsequent superior funding offer because of its sole condition of cheque validation, speaks volumes.

\section{Personality}

The interviewees' perceptions of personality's place in tennis varied. Some considered its impact significant; while others saw it as an element peripheral to self-belief, hard work and motivation. One commonality, however, emerged: that it is not so much one's set personality that has a set influence on the type of player one will be, but rather that success involves an intricate tailoring of one's specific strengths into what I referred to as "the edge". Personal strengths must be combined and correctly weighted to arm players with the strength to face the 'gladiatorial' match setting. The international players emphasised personality characteristics, and provincial players regarded these as the least significant determinants of success. B's perception was that "the positive, confident personality is a big part of" success in tennis. This he related to self-belief and also to what he regarded as an inborn emotionally resilient nature whereby things that go wrong on court just don't affect the resilient player. He emphasised that it was not that the player had to try not to let external things affect him, but rather that "it's just not in you...you're not sensitive to it".

I corroborated the perception of tennis matches as "gladiatorial contests", in which one needs ruthlessness and some kind of "confrontational aggression" (B) to win. A called it the "killer instinct". I termed it "the edge" and matter-of-factly emphasised that it is this that makes champions, that separates the mere players from the winners. Reference was made to players "stalking" future grand slam opponents, purely to unsettle and unnerve them - to establish a dominating presence, to intimidate, to aggress. Any kind of emotional fragility was seen as impossible to have in a winning tennis player: "You don't find weak natures who run away from conflict. That just is not an option" (B).

Many players mentioned the mammoth success John McEnroe made of overtly aggressive, confrontational-style tennis. The dominance of emotion over logic was obvious in his game: "he would be 6-0 5-0 40-0 and make a mistake and smash his racket. Because he's lost one point, and he wants to win every point" (A). The success of McEnroe can be put forward as a good example of the individual strengths theory. For him, anger worked. E observed the grace of McEnroe's explosive method: after shouting about one dubious point, he would play the next with precision and flair - often his best tennis. Another provincial player said of the desirability of emotional reactivity in tennis, "if you get cross and it helps you to win, then get cross" (F). It seems, then, that one needs a non-tennis, non-technical weapon to succeed: an emotional weapon. B called it a willingness to be either overtly or covertly aggressive. This 
might be the "quiet strength" (B), the lack of expressed emotion, the intimidating impenetrability of Sampras and Borg; the continually upbeat body language of Jimmy Connors, even when facing match point; the tenacity, doggedness and fighting spirit of Lleyton Hewitt; the unsettling pace of everything about André Agassi; the relaxed attitude of Roger Federer; the dominating physical presence of Boris Becker; or the monumental rage of McEnroe - anything that upsets the emotional stability of one's opponent.

\section{They have the shots, but do they have the belief?}

One of the most integrated themes to emerge revolved around the ubiquitous notion of selfbelief. All of the players cited it as integral to success, and each of them related personal experiences of its effect on their tennis. Self-belief relates closely to emotional resilience/mental toughness, in that it arises out of what a player honestly believes his capabilities to be; in this sense, it converges with the fundamental psychological concept of self-efficacy. Self-belief in tennis is perceived by the players as one of the most important ingredients of success: if not sufficient, it is without a doubt necessary, in their subjective experience.

At any level in tennis and especially at the very top level, there is minimal variability in the technical and physical ability of players. Thus psychological mechanisms (e.g., self-belief) emerge as the most plausible determinants of success (Ungerleider, 1985 cited in Schomer \& Connolly, 2002) - that which contributes towards "the edge". As a striking example: after attending just six sessions with a clinical psychologist, $\mathbf{H}$ rose in the under 18 rankings from number 11 to number one in South Africa in a matter of tournaments. He said, "The players that I used to lose to I beat them. Everything was exactly the same, but I just believed that I could beat everyone".

\section{Emotional resilience/mental toughness}

All the players spoke of the mental aspect of tennis as being primarily - if not solely emotional. One might expect it would refer to thinking logically about how to beat an opponent, but the players define it rather as an amalgamation of not crumbling under pressure, using anger constructively, believing in oneself, valuing and loving the game to the point of obsession, being flexible, having the gall to intimidate one's opponents, having a fighting spirit, and being proud, passionate, aggressive, positive, confident and dominating. Those who are detached and cold will inevitably fall short of their potential for glory. Not one player failed to emphasise, and voluntarily elaborate on, the importance of being mentally strong in tennis, and all of them had some notion of it as entailing emotional resilience.

Two distinct mental approaches to the game emerged: the desire to win versus the fear of losing. C (recently retired international player and coach) contrasted two of his provincial players in this respect. E has big match temperament: "big points - that's what he loves. And you can see before the match, he's confident." G, though, "doesn't quite have it. Instead of thinking 'I'm way better than this guy, I'll just go out and play my normal game and I'll be fine' - he's worried about losing". Future longitudinal research that focuses on whether this attitudinal distinction can predict success could be useful.

The motivational division relates to research on Neurotic versus Creative players (Syer \& Connolly, 1984). Their polar mental attitudes seem to contribute largely to the latter's more 
frequent success. This evidence further relates to the philosophy of the Inner Game: positive thinking can be just as destructive as negative thinking, as performance decreases when one tries to live up to an expectation. One of Gallwey's tennis students realized: “Compliments are criticisms in disguise! Both are used to manipulate behaviour, and complements are just more socially acceptable!" (Gallwey, 1975: 42-43).

\section{How predetermined is success: Is there a naturally great tennis player?}

All nine players acknowledged that at least some talent is essential for success in tennis. Although the term "talent" was prominent throughout the interviews, only I grappled with its multiplicity of meanings: "What is talented? You can be mentally talented, you can have an eye for a ball, you can hit and serve away, you can be physically talented and be very strong, sharp, fast, flexible. I think the word talented is very overused". A lack of talent in comparison to other players at one's level can, to some extent, be compensated for by extremely hard work and by a "good mind" (see emotional resilience). According to $\mathbf{I}$, "the true winner is one who wins when he's not playing well, and still manages to win when things aren't going right".

This relates to Gilbert and Jamison's philosophy of Winning Ugly (1993): Agassi's former coach and a former professional player himself, he managed some astounding wins over the best tennis players, including Becker, Sampras, Agassi and Connors, without brilliant technique or talent. His method involved extremely thorough mental preparation, and playing his strengths to his opponents' weaknesses. Gilbert's message coalesces with Gallwey's in that he insists one can actually win more by putting in less effort: by not trying so hard. Professional tennis players sometimes throw sets in order to preserve energy and then simply make sure that they win the shots vital to the match outcome. Tennis match point totals are sometimes actually in the loser's favour.

\section{All or...mediocre?}

Players believed that balance is possible and even desirable in professional tennis. It was, however, only seen to be achieved at the cost of greatness. This inevitable compromise, it was suggested, comes with experience and maturing; top players are never "as hardcore at 30 as they were when they were $20 \ldots$. [when] that's their life" (B). Some players, it was said, have consciously chosen balance throughout their careers, for example Wayne Ferreira, South Africa's most prominent player. A and B spoke about Ferreira's renown for "tanking" a match when it is not easily going his way - this means losing intentionally, for which players can be fined. Most professional players are skilled enough to tank subtly, so that although they may be suspected of it, they cannot be blatantly accused. In this way, Ferreira has managed to pick and choose his fights, going with his good days and dismissing his bad. The result has been impressive career longevity and a consistently high enough ranking, in and around the top 20 to 30 in the world, to ensure massive accumulative financial earnings. This approach thus can indeed work.

However, "in tennis it's more valuable to be somebody who plays amazingly well one week and terribly for three weeks", enabling you to break into the rankings during a brilliant week (B). A mediocre, monotonous performance level of tennis means a loss of the obsession, narrow focus, competitive drive, "killer instinct", and excessive attention to detail that create "the edge"(I), which makes a champion. Unlike other sports, such as marathon running in which "you can go to three quarter of your maximum" for most of the race and still win, with 
tennis it is essential to keep "the discipline of mind and body together for as long as it takes. You have to want to win, you can't just go through the motions, you have to lift yourself up to attack the other person and to beat the other person, and if you lose some of that - you're finished" (I). Success therefore involves a committed decision and a very narrowly defined way of life. Balance is, paradoxically, a sacrifice: true greatness cannot be achieved without full commitment.

\section{My best or the best?}

Pete Sampras was named by all interviewees as the most successful tennis player ever. Even if their favourite player was someone else, they all acknowledged Sampras as the undisputed best tennis player of all time. The reasons given were his utter domination of the game (240 consistent weeks at number one), including his seven Wimbledon titles and his grand slam record of 14 titles. His $14^{\text {th }}$ title - the 2002 US Open - was the last professional match Sampras ever played. This confirms that success is perceived as winning. Many players also mentioned his dominant command of such a deep field of competitors (i.e. there were so many worthy competitors "at his heels", A) as compounding his success. Borg was similarly successful in terms of depth of surfaces, and this emerges as another likely indicator of success in tennis.

\section{The paradox of pressure}

Pressure points are inevitable in big matches, and pressure in general will obviously be part of a professional tennis career. It is interesting, then, that the players in this study felt they play their worst when under pressure. A big part of being mentally strong in tennis involves finding a way to deal with pressure, to not put pressure on oneself and to focus on something else. The Inner Game is relevant, emphasizing how players should trust their bodies to hit shots to their full potential, in a relaxed manner, instead of trying too hard, tightening muscles and inevitably using more than necessary (Gallwey, 1975). There is an inverse relationship between pressure and performance. Removing enjoyment from tennis - making it 'work' or focusing too much on competition - usually results in performance deterioration. There is a strong psychological effect of knowing, for example, that another player is 'better' than you, even though this may only be on paper.

\section{Quantitative}

The international players - the most successful in terms of what emerged from this study scored highest on Seriousmindedness (SM) and Planning orientation (PO) subscales, and lowest on the Arousal avoidance (AA) subscale, which may indicate that this latter characteristic is crucial to success. They are less telic dominant than their national counterparts, which supports the notion that paratelic dominant individuals are more successful in sport. The fact that the provincial players are lowest on overall telic dominance and all its subscales, may be due to their age: they have fewer responsibilities, plan less and are willing to take more risks. This is especially possible since the scales are general motivation measures - not specific to sport. It may also indicate their future success in tennis. 
$T A B L E$ 1. METAMOTIVATIONAL DOMINANCE SUBSCALE SCORES: MEANS AND STANDARD DEVIATIONS, BY LEVEL OF TENNIS EXPERTISE (based on descriptive statistics table in Tacon \& Abner, 1993: 167, 170 \& 172)

Means (and standard deviations) for TDS and NDS subscales and for total telic dominance and total negativism, by level of expertise

\begin{tabular}{|lccccccc|}
\hline & SM & PO & AA & TTD & PN & RN & TN \\
\hline \multirow{2}{*}{ Provincial } & 4.5 & 5.25 & 5.5 & 15.25 & 1 & 5.75 & 6.75 \\
& $(0)$ & $(0.35)$ & $(1.41)$ & $(1.77)$ & $(1.41)$ & $(1.71)$ & $(1.5)$ \\
National & 5.5 & 6 & 7.5 & 19 & 3 & 4 & 7 \\
& $(5)$ & $(4.24)$ & $(4.95)$ & $(14.14)$ & $(4.24)$ & $(5.66)$ & $(10)$ \\
\multirow{4}{*}{ International } & 6 & 6.5 & 5.17 & 17.67 & 2.33 & 3 & 5.33 \\
& $(2)$ & $(1.32)$ & $(3.75)$ & $(1.15)$ & $(1.53)$ & $(2.65)$ & $(1.15)$ \\
\hline
\end{tabular}

Unexpectedly, the national players were, on average, the most negativistically dominant. However, the fact that there were only two players in this category and that it had an uncharacteristically high standard deviation of 10, demanded an examination of the raw data, which revealed that one player obtained a negativism score of 0 , while the other scored $14-$ the highest individual raw score recorded. This could represent an anomaly, and research with far greater subject pools would be needed to investigate further. The provincial players followed with $\mathrm{TN}=6.75$ and the international players scored the lowest, with $\mathrm{TN}=5.33$. However, subjects in the latter group had relatively homogenous $\mathrm{TN}$ scores $(\mathrm{sd}=1.15)$, which inspires confidence that this group's motivational dominance has been most accurately represented.

\section{Limitations and cautions}

This study was limited in that qualitative research has been argued to be prone to bias and has been criticised because it does not easily apply itself to generalisation and standardisation. However, this presents minimal difficulty to a focused area of research that aims to explore subjective perceptions and find commonalities and differences amongst them. The small, predominantly male sample and the fact that questionnaires were administered to such a small group constitute other limitations that could be improved upon in future research.

\section{CONCLUSION}

What has emerged from the present study is that, especially at top levels, tennis is predominantly played in the minds of the two players. Most players competing at this level are likely to be equal in technique, but not all will have the personality and mental attributes that give them "the edge" and that ensure victory. The results of this study show that according to the subjective perceptions of players, mental aspects and personality characteristics can determine a successful outcome in world class tennis. Of these aspects, self-belief emerged as particularly salient. The Inner Game teaches that,

"there are in fact two games going on on the court. There is of course an outer game played with our external opponent, but there is an inner game as well: it takes place in the mind of the player and is played against such elusive opponents as nervousness, self-doubt and lapses of concentration. It is a game played on and off the court every 
day. In short, it is a game played by the mind against its own bad habits." (Gallwey, 1975)

This research study has provided new ideas about how individual players at the top of their respective levels subjectively perceive the components and determinants of success. The integrative themes could serve as starting points for further qualitative sport psychology research in this area.

Qualitative research points to the dynamic, changeable and indefinable aspects of people, and thus differs from cognitive psychology, which explores the measurable and definable elements of human nature. Thus although the qualitative nature of this study suggests that it is difficult to know exactly how success can be achieved in tennis, a strong theme that emerged from the analysis was the image of the tennis player as an individual, dynamic organism who, on realising his talent for, commitment to and love of tennis, must work out the strengths and weaknesses in his personality and mind, and arrange these to the best advantage for the aggressively competitive nature of professional tennis.

The empirical literature was generally well supported by the results of the present study, in a way that made it more meaningful and applicable. Furthermore, new and relevant areas of interest were established and this study suggests the need for both better training techniques in terms of the mental side of tennis and for the rebuilding of South African tennis as a whole.

\section{REFERENCES}

APTER, M.J. (2004). Reversal theory: What is it? [http://www.reversaltheory.org.RT_TheoryIntro.htm]. Retrieved 24 August 2004.

BABBIE, E.R. (2001). Qualitative data analysis. In E.R. Babbie (Ed.), The practice of social research. Belmont: Wadsworth.

DIEHM, R. \& ARMATAS, C. (2003). Surfing: An avenue for socially acceptable risk-taking, satisfying needs for sensation seeking and experience seeking. [Electronic version]. Personality and individual differences, 36(3): 663-677.

GALLWEY, W.T. (1975). The inner game of tennis. London: Jonathan Cape.

GILBERT, B. \& JAMISON, S. (1993). Winning Ugly. New York, NY: Fireside.

JANESICK, V.J. (2004). Stretching exercises for qualitative researchers $\left(2^{\text {nd }}\right.$ ed.). Thousand Oaks, CA: Sage.

KERR, J.H. (1997). Motivation and emotion in sport: Reversal theory. Sussex: Psychology Press.

KREMER, J.M.D. \& SCULLY, D.M. (1994). Psychology in sport. London: Taylor \& Francis.

MILLER, J. \& GLASSNER, B. (1997). The "inside" and the "outside": Finding realities in interviews. In D. Silverman, Qualitative research: Theory, method and practice (98-111). London: Sage.

MORAN, A.P. (1996). The psychology of concentration in sport performers: A cognitive analysis. Sussex: Psychology Press.

MOUTON, J. (2001). How to succeed in your master's and doctoral studies: A South African guide and resource book. Pretoria: Van Schaik.

SCHOMER, H.H., \& CONNOLLY, M.J. (2002). Cognitive strategies used by marathoners in each quartile of a training run. South African Journal for Research in Sport, Physical Education and Recreation, 24(1): 87-99. 
SQUIBB, J.J. \& SCHOMER, H.H. (2004). Perceptions of success among South African soccer players: An exploratory study. South African Journal for Research in Sport, Physical Education and Recreation, 26(2): 17-31.

SYER, M. \& CONNOLLY, C. (1984). Sporting body, sporting mind. Cambridge: Cambridge University Press.

TACON, P. \& ABNER, B. (1993). Normative and other data for the Telic Dominance Scale and the Negativism Dominance Scale. In J.H. Kerr, S. Murgatroyd \& M.J. Apter (Eds.). Advances in reversal theory (167-208). Amsterdam: Swets \& Zeitlinger.

Dr. Helgo Schomer: Department of Psychology, University of Cape Town, Rondebosch 7700, Republic of South Africa. Tel.: +27 (0)21 650 3433, Fax.: +27 (0)21 650 4104, Email: schomer@humanities.uct.ac.za

(Subject editor: Prof. J.R. Potgieter) 


\section{NOTES}

